\title{
Nghiên cứu hợp tác quốc tế thường tập trung vào các kết quả an toàn
}

\author{
Hồ Mạnh Toàn
}

A.I. for Social Data Lab

Hà Nội, 09-03-2019

Những năm gần đây, các nghiên cứu hợp tác quốc tế ngày một tăng trong khoa học, và được chú ý trong khoa học. Tại các quốc gia có nền khoa học phát triển, số lượng các nghiên cứu hợp tác quốc tế đã tăng gấp 10 lần kể từ năm 1991 [1]. Đối với các quốc gia đang phát triển như Việt Nam, hợp tác quốc tế là một cách tốt để tăng sản lượng và năng suất. Nghiên cứu dựa trên dữ liệu từ ISI Web of Science đã chỉ ra trong giai đoạn 2001-2015, có đến 77\% công bố của Việt Nam có hợp tác quốc tế [2]. Trong khi đó, dữ liệu KHXH\&NV Việt Nam từ 2008 - 2018 thì chỉ ra 90\% tác giả hợp tác viết ít nhất 1 nghiên cứu với các tác giả khác [3].

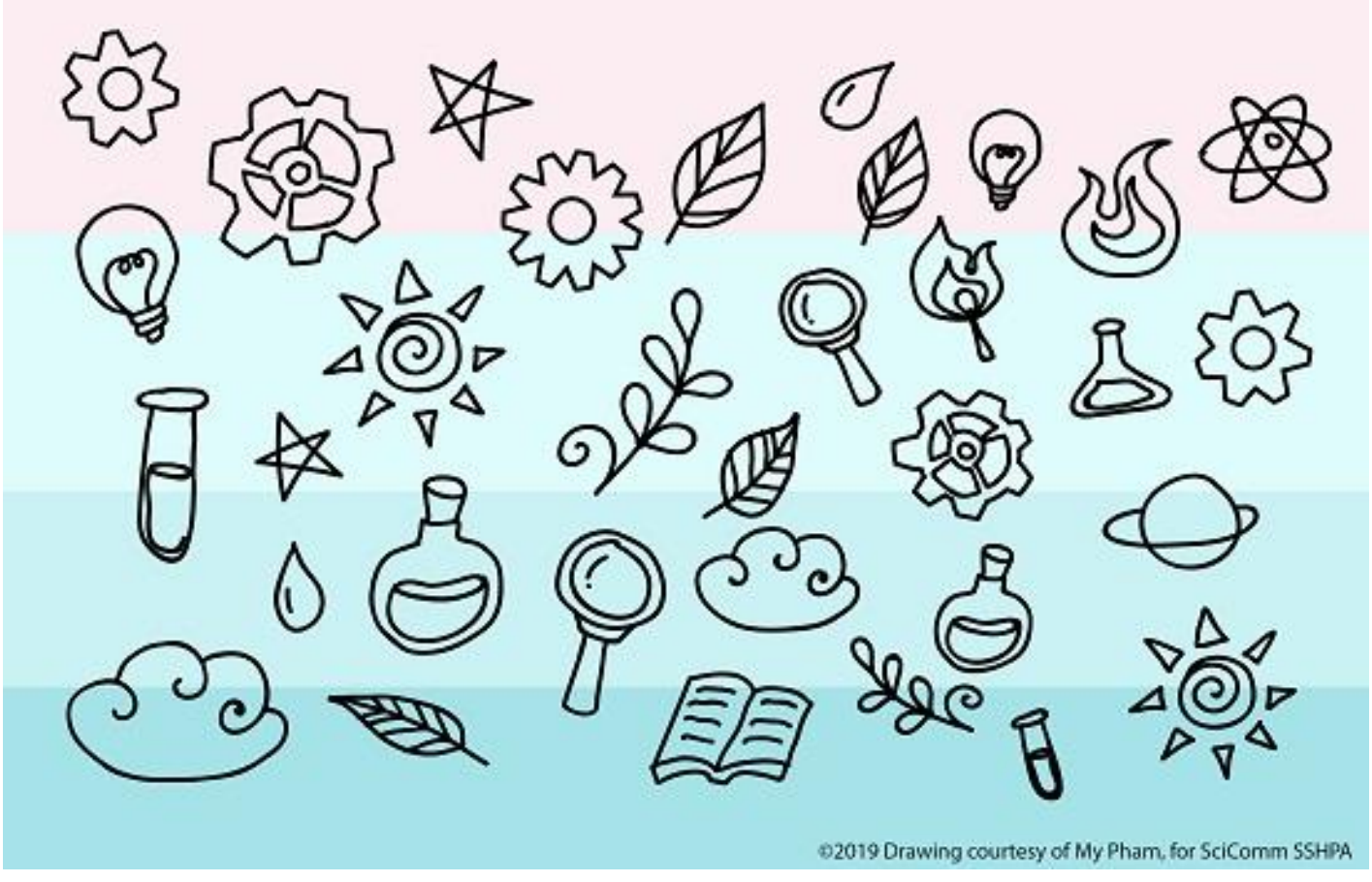

Mặc dù giải quyết các vấn đề về năng suất, liệu các nghiên cứu hợp tác quốc tế này có thể giúp đẩy mạnh các ý tưởng hay phát kiến quan trọng với khoa học? Nhóm ba nhà nghiên cứu Caroline S. Wagner (Ohio State University, Hoa Kỳ), Travis A. Whetsell (Florida International University, Hoa Kỳ) và Satyam Mukherjee (Indian 
Institute of Management, Ấn Độ) mới đây đã chỉ ra thực tế các nghiên cứu hợp tác thường trốn tránh các kết quả mới lạ [4].

Để rút ra kết luận này, nhóm nghiên cứu đã phân tích dữ liệu hơn 4 triệu nghiên cứu trong giai đoạn 2001 - 2005 từ Web of Science. Sau đó, nhóm chứng thực kết quả bằng cách lặp lại nghiên cứu với dữ liệu từ CSDL Scopus, đồng thời sử dụng thêm phương pháp đo khác. Kết quả cho biết, các nghiên cứu có sự tham gia của càng nhiều quốc gia thì mức độ thông thường của nghiên cứu càng cao. Yếu tố này có mối liên hệ nhất định với vấn đề nhóm lớn, nhóm nhỏ được đề cập trong một nghiên cứu mới đây. Nghiên cứu này cho thấy các nhóm nhỏ cũng thường mang đến các quả mới lạ hơn so với nhóm đông người [5].

Thông qua các lý thuyết xã hội học, các tác giả cho rằng khi một nhà khoa học trở nên nổi tiếng, thì nhà khoa học đó sẽ thường làm việc ở mức độ quốc tế, và lúc đó các nghiên cứu sẽ thường nhằm mục đích giữ danh tiếng hơn là tạo ra danh tiếng. Ngoài ra, các yếu tố thực tiễn khác như chi phí cao, phụ thuộc vào công nghệ, hay vấn đề ngôn ngữ cũng khiến các nghiên cứu quốc tế thường không nhắm đến các kết quả mới lạ.

Thực tế cho thấy các nhà hoạch định chính sách thường đề cao khả năng hợp tác quốc tế. Tuy nhiên, kết quả cho thấy có sự đánh đổi rõ rệt và vì thế, để đảm bảo chi phí khoa học ở mức hợp lý [6], các yếu tố về hợp tác cũng cần được xem xét kĩ lưỡng.

Notes: Published in SSHPA.

\section{References:}

[1] Wagner, C. S., Travis, W., \& Mukherjee, S. (2019). Novel findings rare from international collaborations. Nature Index, Retrieved from: https://www.natureindex.com/news-blog/novel-findings-rare-frominternational-collaborations

[2] Nguyen, V. T., Thao, P. H., \& Le, V. U. (2017). International collaboration in scientific research in Vietnam: an analysis of patterns and impact. Scientometrics, 110(2), 1035-1051, DOI: 10.1007/s11192-016-2201-1, URL: https://link.springer.com/article/10.1007/s11192-016-2201-1.

[3] Vuong, Q. H., La, V. P., Vuong, T. T., Ho, M. T., Nguyen, H. K. T., Nguyen, V. H., ... \& Ho, M. T. (2018). An open database of productivity in Vietnam's social sciences and humanities for public use. Scientific data,5, DOI: 10.1038/sdata.2018.188, URL: https://www.nature.com/articles/sdata2018188.

[4] Wagner, C. S., Travis, W., \& Mukherjee, S. (2019). International research collaboration: Novelty, conventionality, and atypicality in knowledge 
recombination. Research Policy, DOI: 10.1016/i.respol.2019.01.002, URL: https://www.sciencedirect.com/science/article/abs/pii/S00487333193000 46.

[5] Wu, L., Wang, D., \& Evans, J. A. (2019). Large teams develop and small teams disrupt science and technology. Nature, 566, 378-382, DOI: 10.1038/s41586019-0941-9, URL: https://www.nature.com/articles/s41586-019-0941-9

[6] Vuong, Q. H. (2018). The (ir)rational consideration of the cost of science in transition economies. Nature Human Behaviour, 2, 5, DOI:10.1038/s41562017-0281-4, URL: https://www.nature.com/articles/s41562-017-0281-4. 